\title{
When and Where Is Transdisciplinary Engineering Applied in Projects? A Case Study
}

\author{
Alexander KHARLAMOV ${ }^{\mathrm{a}, 1}$, Glenn PARRY ${ }^{\mathrm{a}}$ and Linda NEWNES ${ }^{\mathrm{b}}$ \\ ${ }^{a}$ Surrey Business School, United Kingdom \\ ${ }^{b}$ University of Bath, United Kingdom
}

\begin{abstract}
Transdisciplinary engineering (TE) is gaining attention in academic literature and comes with the underlying assumption of being the next evolutionary step for incorporating engineering solutions in practice. We seek to answer the question of when TE is appropriate and what the conditions are for efficient applications of TE in practice. A framework for analysis is constructed integrating TE with theory of communication and strategic paradox. The framework is used as a lens in a single explorative case of an multi-university research project. The project brings together researchers from a diverse range of disciplines, working together to create a novel device that could have a transformative impact on specific cancer healthcare. Data is collected using structured interviews with project researchers. The main finding from the case study is that TE does not appear to be employed at all levels of abstraction. In this case TE is found to be employed at the strategic level, while tactical and operational levels adopt traditional approaches to working. Effective TE relies heavily on the relationship between specialisation and generalisation. We identify two main roles when it comes to people; specialists and generalists. Specialists (e.g. healthcare, pharmaceuticals \& biotechnology) must be able to understand the general picture while the Generalists (e.g. business; operations) must be aware of the requirements and limitations of Specialists. Generalisations for practice and further research are discussed. The main contribution of the work is a framework for analysis of TE.
\end{abstract}

Keywords. Organizational Theory, Objects, Case Study, Engineering, Framework

\section{Introduction}

Modern problems are becoming increasingly complex and the pathway to solutions is in most cases transdisciplinary. Transdisciplinarity is working beyond disciplinary boundaries, applying sciences in practice to shape social systems and ultimately have value and meaning for the society [1], [2], e.g. [3]. The implication is that transdisciplinarity working is an essential approach when seeking solutions to most of the modern problems [1]. Transdisciplinary Engineering (TE) is the incorporation of complex engineering solutions to solve a problem in practice. Although TE can be considered to be the process of integrating a broad set of knowledge to solve problems in practice, it is a rather ambitious aim. It is unclear how to apply TE working in practice and what its impact is in real-world situations.

\footnotetext{
${ }^{1}$ Corresponding author, Email: a.kharlamov@surrey.ac.uk.
} 
In this paper, we seek to develop a framework for TE in practice. It is based on the first transdisciplinary system proposed by Jantsh [2], [3] which focuses on education. To enable its application to practice we adopt the Organizational Theory perspective [4]. To accommodate the inherent complexity of TE, we focus on the theoretical subset of the Theory of Paradox [5] in organizations which observe the variety of conflicting objectives that must be achieved simultaneously for the organization to succeed. The most common example of such paradoxes in TE is the need to be both a niche expert and at the same time have a very broad set of skills and knowledge to operate beyond the niche. Finally, in order to understand the internal dynamics of TE organizations, we explore the role of different knowledge sharing objects in TE working [11]. We identify boundary, technical and epistemic objects and how they support TE organizations.

The paper is structured as follows: After this introduction we present an overview of the background theory with reference to the main contributions on each of the fields. We then proceed to integrate the background theory in a single framework. We proceed with the methodology section where the framework is used to create a structured interview protocol. The following section presents the results and analysis and we close the paper with the discussion and the conclusions.

\section{Background theory}

\subsection{Transdisciplinarity}

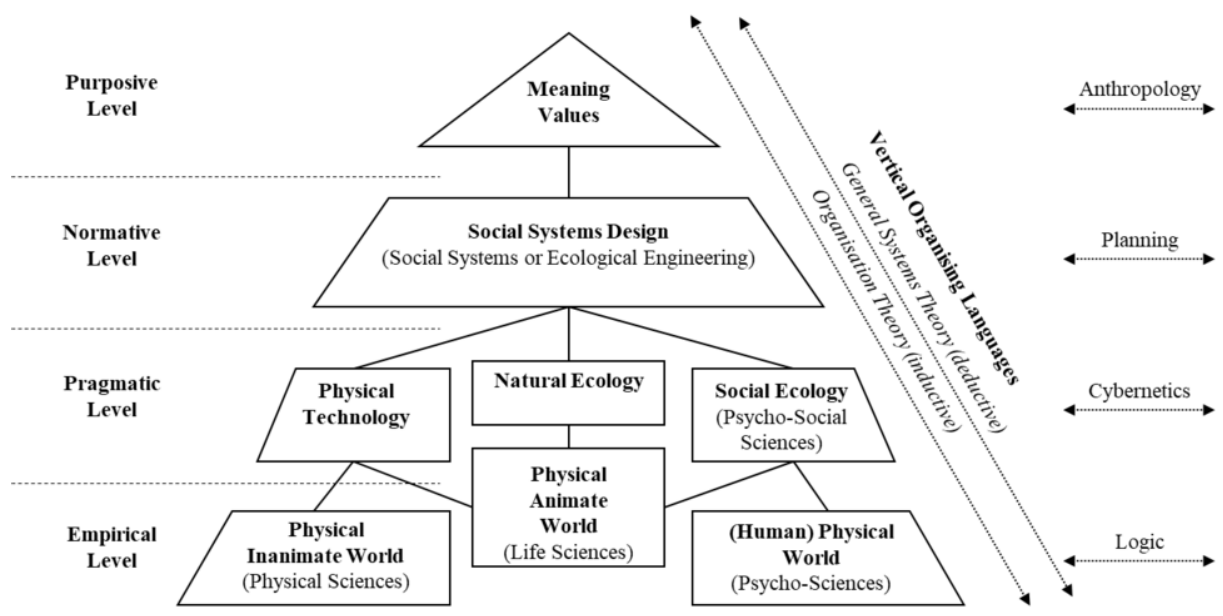

Figure 1. The education/innovation system, viewed as a multi-level multi-goal, hierarchical system [2, p. 104]

In his semial work on transdisciplinarity Jantsch [3, p. 7] considers the structure (see Figure 1) of a university at four principal levels: empirical, pragmatic, normative and purposive levels and defines a transdisciplinary approach as "coordinated as a multilevel multigoal hierarchical system" with a "generalized axiomatics and mutual enhancement of disciplinary epistemology". Similarly, according to [1, p. 1] "Transdisciplinarity today is characterized by its focus on "wicked problems" that need creative solutions, its reliance on stakeholder involvement, and engaged, socially responsible science." Jantsch defines a framework for education that aims to achieve societal value or meaning for the 
stakeholders. Building upon this Jantsch identifies a hierarchy of disciplinarity: multi-, pluri-, cross-, inter- and trans-disciplinarity where the latter is the ultimate level of integration where working is done across all levesl in the structure.

\subsection{Theory of Paradox}

Sitting under the umbrella of the grand Organisational Theory [4], Theory of Paradox examines and seeks to address how organisations can manage and create strategy to address contradicting demands [5]. Paradoxes are tensions that persist and that organisations must handle in order to remain competitive [5]. Organizing raises multiple tensions, such as collaboration-control [6], individual-collective [7], flexibilityefficiency [8], exploration-exploitation [9], and profit-social responsibility[10]. In the case of TE we perceive a potential paradox in the need for individuals to be niche experts and also generalists able to work across discipines.

\subsection{Objects}

In the management and organisation of knowledge production, objects are often used [11]. Different forms of objects are identified, Boundary, Technical and Epistemic [12], that each perform a function in the creation and management of both knowledge and people.

The boundary object is one unit that is open to different interpretations, but provides a holding ground for ideas for communication, translation and standardisation of meaning. Boundary objects are employed to manage and answer questions at the boundary of different communities where novelty could enter a system [13, p. 566] They are generally understood to represent concrete concepts with stable meaning. Their role over time is as a guide, enabling coordination across communities of practice. The subject-object relations are multiple and are used in direct, cross boundary interactions between multiple subjects [12]. Boundary objects include schedules, Gantt Charts, machines and parts.

Technical objects are also fixed in nature, being complete and unproblematic instruments that don't change over time. They are the stable objects employed by the subject expert [12]. Examples of technical objects are tools and instruments, e.g. computers.

'Epistemic objects' [11] are objects of research that can engage individuals and be used to capture knowledge that may be beyond the immediate conscious understanding of the interviewee. Objects may include natural history specimens, maps, or models. It is only in the process of discussion that their insight unfolds. The nature of epistemic objects is abstract and characterised by lack and incompleteness. This type of object may be employed in different ways and is continuously evolving. Over time its role may remain 'in-flux', changing to better enable knowledge work. The relationship between the subject and object is dyadic, characterised by particular by how is is used [12].

Objects are multi-dimensional in nature and are used across rather than within practices [12]. 'Phenomenon and instrument, object and experience, concept and method are all engaged in an ongoing process of mutual instruction' (Rheinberger 2010a: 31). [14]. 


\section{Integrative framework}

To examine TE in practice, including an examination of paradox and use of objects it is necessary to create a single integratative conceptual framework (see Figure 2). To achieve this aim we conceptualise TE projects as an organization that is managed. We adopt the set of definitions of transdisciplinarity according to the system first proposed by Jantsh [2], [3]. However, modification is required as Jantsh [2], [3] focuses on education, and the definitions and the hierarchical relationships between disciplines are insufficient if we are to apply the framework to the engineering practice [1].

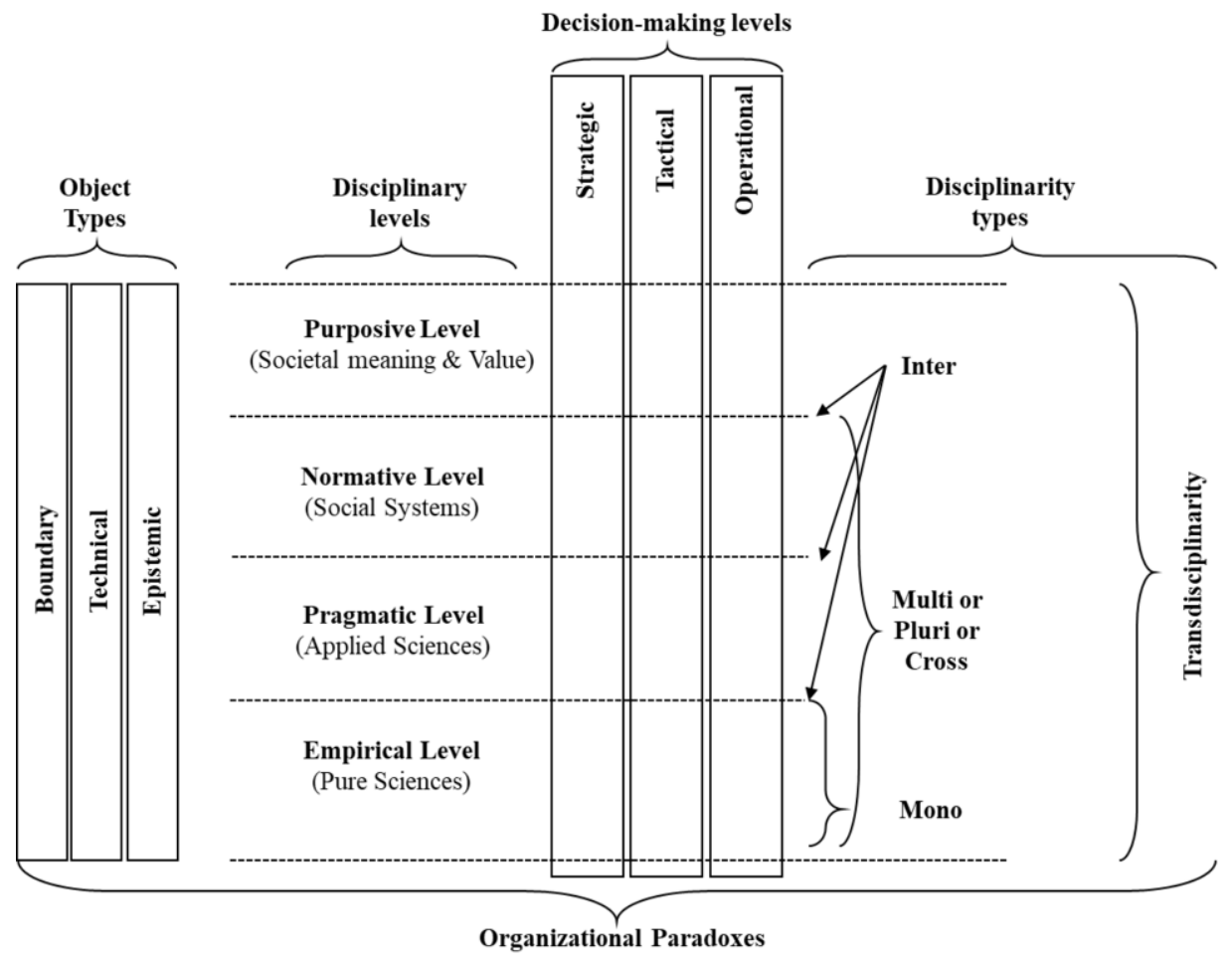

Figure 2. Integrative framework.

To adopt the TE framework to practice we rely on organisational theory focusing on the Theory of Paradox [5]. The theory of paradoxes in organizations enables us to adopt a wholistic overview of the TE system. This allows examination of internal tensions and mutually conflicting targets arising from the complex nature of coordinating multiple levels and multiple goals towards a common purpose. To structure TE work, we utilise operations management decision-making levels, namely strategic, tactical and operational, see: [15], which describe different types of routine decisions.

Finally, in order to capture the dynamics of sharing and management of meaning between subjects, we explore the potential role of objects in the organization [12], specifically boundary, technical and epistemic objects. 


\section{Context}

Many research projects bring together individuals from multiple backgrounds to work towards a common goal [3]. University based research projects that are TE are encouraged, and a single example forms the basis of the exploratory work here. To explore transdisciplinary working in practice we adopt the structure proposed by Jantsch (1970) as it comes from the University structure, providing a formal conceptualisation of a transdisciplinary system. To align case with theory we must view the transdisciplinary team as an organisation. We seek to examine paradox as a central assumption is that the contradicting goals and persistent tensions observed in organisations (e.g. Smith and Smith 2016), will be observed in transdisciplinary teams, which refers back to the exploration/exploitation tension [9]. Similarly, during transdisciplinary working team work (collective) is paramount, but so is individual/autonomous working which illustrates the individual-collective tension [7].

Within organisations, knowledge is shared via objects: boundary, technical and epistemic objects. These objects are crucial for mutual understanding and effective communication between subjects [12]. This is important because communication is considered to be the main enabler of transdisciplinary working [1]. Understanding the mechanism behind communication between subjects via objects can greatly improve transdisciplinary team working in practice.

\section{Methodology}

An explorative single case study [16] approach is adopted, directly involving researchers in the process. A specific situation is explored in real-time and methods employed to understand the problem and suggest changes [17]. An action research approach is adopted, which is a special type of case study involving participation in the change [18]. Researchers and clients actively collaborate through a project, from the initial diagnosing to the final deployment [19]. Action research is appropriate when the focus of the research is on learning about changes and making improvements over time [18].

The specific case selected is that of the Optimising Me Manufacturing System (OMMS) project. As part of the EPSRCs New Industrial Systems, OMMS is developing a healthcare microfactory that provides on-the-body manufacturing of therapeutics, bringing together researchers from a diverse range of disciplines to work together to create transformative impact on manufacturing industries. Qualitative data is collected though structured interviews [17], [20]. The interview structure is built on the integrative framework (see Figure 3) and is listed in Table 1. Interview transcripts are coded then analysed using matrix analysis [17], [20]. 
Table 1. Interview Structure.

\begin{tabular}{|c|c|}
\hline Segment & Question \\
\hline $\begin{array}{l}\text { Overview + Epistemic/ } \\
\text { Technical/ Boundary } \\
\text { objects [12], [21] }+ \\
\text { Theory of Paradox [5] }\end{array}$ & $\begin{array}{l}\text { 1. Could you please describe the project from your perspective? } \\
\text { 2. Is there anything that you could use to assist you in explaining the } \\
\text { project to non-expert audiences? What would it be and why? } \\
\text { 3. What is your specific role within the project? }\end{array}$ \\
\hline Intro section 2 & We will now discuss skills required for the OMMS project. \\
\hline Theory of Paradox [5] & $\begin{array}{l}\text { 4. Could you elaborate by order of importance what are the main skills } \\
\text { required for the success of the project? } \\
\text { 5. What are the main skills that you bring to the OMMS project? } \\
\text { 6. Would you identify yourself as a niche expert or you have a broad set of } \\
\text { skills? What about the rest of the team? }\end{array}$ \\
\hline Intro section 3 & The following part focuses on what enables OMMS to function: \\
\hline $\begin{array}{l}\text { TD } \\
{[1],[3]}\end{array}$ & $\begin{array}{l}\text { 7. Does the project rely on pure sciences (maths, physics, psychology)? } \\
\text { Can you give some examples? } \\
\text { 8. Does the project rely on any applied sciences? Which ones and why? } \\
\text { 9. Does the project have any impact on regulation, policy or law? How? } \\
\text { 10. Does the project have direct meaning and value for the society? Why? }\end{array}$ \\
\hline $\begin{array}{l}\text { Inter/Trans disciplinarity } \\
{[1],[3]}\end{array}$ & $\begin{array}{l}\text { 11. From the following sentences, which one would best describe what } \\
\text { OMMS is doing and why? } \\
\text { I. The project only applies pure sciences in practice } \\
\text { II. The project focuses on applied sciences to shape social systems (e.g., } \\
\text { law, regulations) } \\
\text { III. The project focuses on changing social systems because it has meaning } \\
\text { and value for the society } \\
\text { IV. The project applies pure sciences in practice to shape social systems } \\
\text { due to its meaning and value for the society } \\
\text { V. None of the above }\end{array}$ \\
\hline Intro section 4 & $\begin{array}{l}\text { For the final part, we will look at different types of work performed by the } \\
\text { OMMS team. }\end{array}$ \\
\hline $\begin{array}{l}\text { Strategy @ } \\
\text { Mono/ Multi/ Cross/ } \\
\text { Inter/ Trans [1], [3] } \\
+ \text { Theory of Paradox [5] }\end{array}$ & $\begin{array}{l}\text { 12. From the following sentences, which one would best describe how the } \\
\text { OMMS team works to define the overall direction of the project and } \\
\text { why? } \\
\text { I. High specialisation within one discipline in isolation without relation to } \\
\text { other disciplines of approaches } \\
\text { II. A variety of disciplines, offered simultaneously, but without making } \\
\text { explicit possible relationships between them } \\
\text { III. More than one disciplines are coordinated } \\
\text { IV. Coordination at multiple levels towards multiple goals towards a } \\
\text { common purpose }\end{array}$ \\
\hline $\begin{array}{l}\text { Tactic @ } \\
\text { Mono/ Multi/ Cross/ } \\
\text { Inter/ Trans [1], [3] } \\
+ \text { Theory of Paradox [5] }\end{array}$ & $\begin{array}{l}\text { 13. From the following sentences, which one would best describe how the } \\
\text { OMMS team plans the work within the project and why? } \\
\text { I. High specialisation within one discipline in isolation without relation to } \\
\text { other disciplines of approaches } \\
\text { II. A variety of disciplines, offered simultaneously, but without making } \\
\text { explicit possible relationships between them } \\
\text { III. More than one disciplines are coordinated } \\
\text { IV. Coordination at multiple levels towards multiple goals towards a } \\
\text { common purpose }\end{array}$ \\
\hline $\begin{array}{l}\text { Operational @ } \\
\text { Mono/ Multi/Cross/ } \\
\text { Inter/ Trans [1], [3] } \\
\text { + Theory of Paradox [5] }\end{array}$ & $\begin{array}{l}\text { 14. From the following sentences, which one would best describe how the } \\
\text { OMMS team executes the work within the project and why? } \\
\text { I. High specialisation within one discipline in isolation without relation to } \\
\text { other disciplines of approaches } \\
\text { II. A variety of disciplines, offered simultaneously, but without making } \\
\text { explicit possible relationships between them } \\
\text { III. More than one disciplines are coordinated } \\
\text { IV. Coordination at multiple levels towards multiple goals towards a } \\
\text { common purpose }\end{array}$ \\
\hline End & Thank you for your time \\
\hline
\end{tabular}




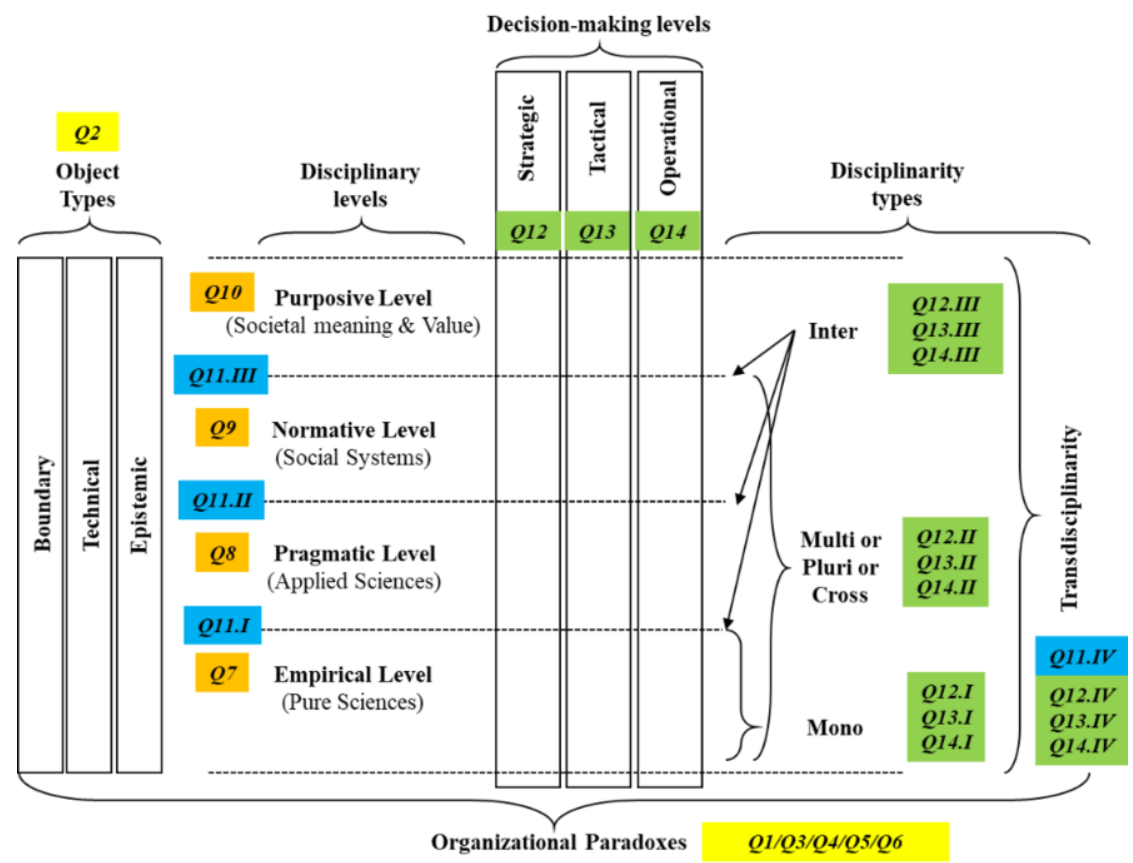

Figure 3. Overlay of the integrative framework and interview questions (see interview structure in table 1).

\section{Results \& Analysis}

Nine structured interviews capture the perceptions of the majority of the OMMS project team. Overall, participants describe the project from a variety of perspectives, all sharing a perception of the projects societal value (curing cancer) and practical requirements, specifically the need for treatment to be cheaper and more accessible. Each interviewee has a specific role, yet the majority express interest, knowledge and understanding of other researchers work. In terms of percieved skills necessary for the success of the project, the predominant is communication. Communication further breaks down into ability to provide good explanations, collaborate, listen, and learn quickly. Niche expertise comes second after communication as the complexity and sophistication of the project requires in-depth knowledge in a field that is then integrated into the overall solution. The least predominant skills identified by interviewees were business understanding and project integration. This ommision came despite interviewees all identifying cost and the challenges of taking their product to market in their description of the project.

Regarding individual skills, all clearly defined their expertise, but only three mentioned their soft skills such as communication, openness and ability to integrate the project. So although 8 out of 9 identify communication as the main skill required for project success, only three report bringing that skill to the team. 


\subsection{Transdisciplinarity}

In terms of transdisciplinarity, the OMMS project was predominantly seen as TE, with 7 of the respondents stating that the project applies pure sciences in practice to shape social systems due to its meaning and value for the society. We further verify more aspects essential to TE from alternative perspectives.

The project relies on pure sciences; specially chemistry, physics, biology, psychology and maths were mentioned. Further, these sciences are described in terms of their application, with engineering at the core of the project. Regarding the impact on regulation, policy or law, 5 of the interviewees believe it will have impact if the project is successful, but the rest does not think it has any direct impact. However, in terms of meaning and value for the society, unanimous agreement was given that it does, and it is one of the main motivating factors for each individual in the project.

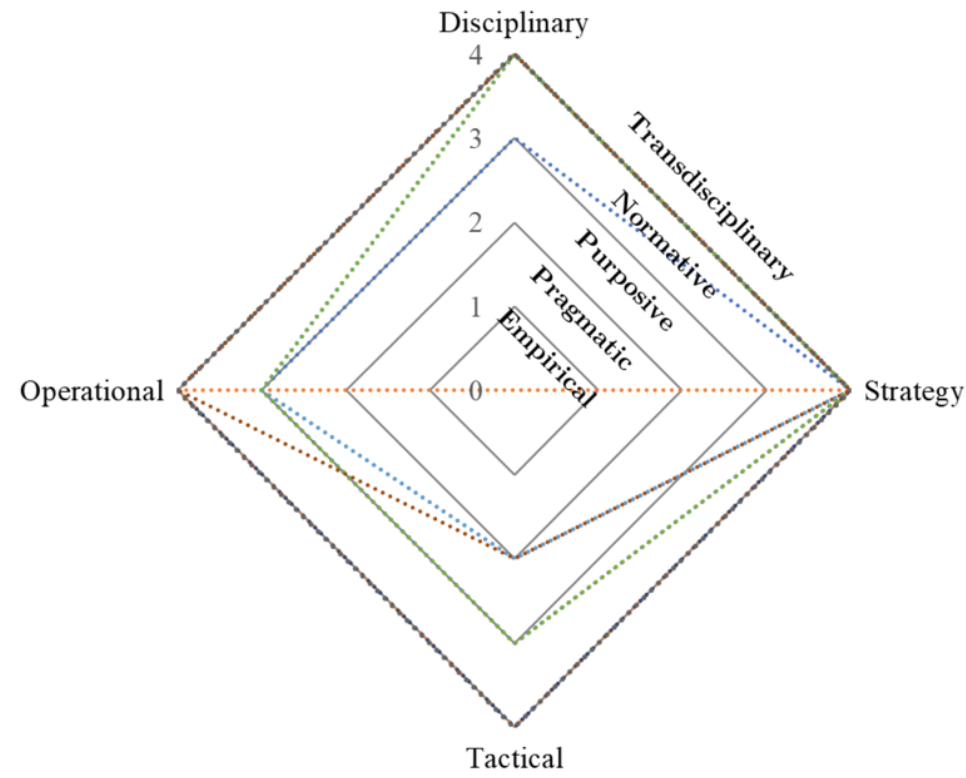

Figure 4. Breakdown of work in terms of disciplinary, strategic, tactical and operational levels.

Regarding the different types of work, specifically strategic, tactical and operational decisions, at a strategic level, all coordinate at multiple level with multiple goals leading to a common purpose. One respondent explicitly stated that at each meeting the purpose is restated so everyone remembers what the overall direction of the project is. Regarding tactical decisions, half of the respondents report planning work at an inter-disciplinary level with more than one discipline coordinated. Two interviewees perceive that the project is multidisciplinary, where a variety of disciplines co-exist. Three interviewees consider the project work at a transdisciplinary level. Finally, operational work is identified as happening at an interdisciplinary level by 5 respondents, while 4 believe it is transdisciplinary with disciplines seamlessly coordinated towards a common purpose. A summary of the responses is illustrated in Figure 4 in terms of different disciplinary levels and types of work where each interviewee is represented by a different coloured line. 


\subsection{Paradoxes}

The main paradox identified comes from each interviewee reporting on their niche expertise, yet claiming to have a broad set of skills. This illustrates the conflicting need in TE projects for both depth and breadth of knowledge. In terms of peers, 5 people perceived that the project team members each had a broad skillset, whilst 4 preceived that the team are niche experts.

The second paradox can be identified in the way that the work is performed, specifically both working independently and working as a group. Most respondents reported working within their subject, performing a specific task. However, they consider that the operational level work is being done at an interdisciplinary or transdisciplinary level. Building up on this paradox, only one respondent referred to the importance of integration between subjects and independent teams.

\subsection{Objects}

Regarding objects, a variety of objects are identified. Boundary objects were extensively used with videos, presentations, animations, cartoons, process maps and flowcharts mentioned. These support communication between teams, across subjects and beyond the project participants when engaging with the broader community. Technical objects include biosensors used, microfluidic devices, prototypes and analogous devices (pacemakers, insulin pumps and wearable trackers), which are concrete and objective examples of objects relevant to understanding different dimensions of the project. Finally, epistemic objects include an evolving visualisation of the manufacturing device, sensor chips and components, which were all used to attact interest, share knowledge and support discussion of abstract ideas.

\section{Conclusion}

This paper contributes to narrowing the gap between the conceptualization of TE and practice. A case study employs a novel theoretical framework that integrates TE [4], strategic paradox [5],[9] and helps identify the objects [12] used in project management and communication.

In this single case TE is perceived as mainly applicable at the strategic level, while traditional approaches to organising work are found at the tactical and operational level [15]. At the operational level subjects believe it is necessary to take a reductionist approach, breaking down complex tasks into simple actions, which is distant from the wholistic proposition of TE working.

The main paradox [6] faced by reserachers is the need to be a niche expert and have generalised knowledge [7] in ordert to understand the whole project. The second paradox identified is the balance between individual and group working, as both are required to achieve outcomes [9]. We identify two main roles, specialists and generalists. Specialists focus on the application of core sciences in practice (healthcare, pharmaceutical, biotechnology). Generalists focus on project integration and its broader implication to society, viability and feasibility (business, manufacturing and operations). The two groups co-exist through working towards open communication. Specialists must understand the project overview, while the generalists must know the detail of the diverse core-sciences to understand project requirements, limitations and possibilities. 
Regarding different objects, boundary objects identified include presentations, video, animations, cartoons, process mapping and flowcharts. Epistemic objects identified include electronic chips and components, used to show people to convey meaning and kindle interest. Finally, technical objects include biosensors, microfluidic devices and analogous devices such as pacemakers, insulin pumps and activity trackers.

Future research beyond this single case study is required to test and refine the proposed framework. A recognised limitation of the framework is it does not examine the mechanisms behind communication, identified to be a core skill for TE working. To examine communication future work will examine the role of transactive memory in organizational groups e.g. [22], and also explore how content, consensus and accuracy affect TE group performance.

\section{References}

[1] J. H. Bernstein, Transdisciplinarity: A Review of Its Origins, Development , and Current Issues, Journal of Research Practice, Vol. 11, Issue 1, Article R1, July 2015.

[2] E. Jantsch, Interdisciplinarity Problems of Teaching and Research in Universities. Paris: ERIC, 1972.

[3] E. Jantsch, Inter-disciplinary and transdisciplinary university: A systems approach to education and innovation, Policy Sci., vol. 1, no. 4, pp. 403-428, 1970.

[4] G. R. Jones, Organizational theory, design, and change. Pearson, Upper Saddle River, 2013.

[5] W. K. Smith and W. K. Smith, Toward A Theory of Paradox: A Dynamic Equilibrium Model of Organizing, Acad. Manag. Rev., vol. 36, no. 2, pp. 381-403, 2016.

[6] C. Sundaramurthy and M. Lewis, Control and Collaboration: Paradoxes of Governance, Acad. Manag. Rev., vol. 28, no. 3, pp. 397-415, 2003.

[7] J. K. Murnighan and D. E. Conlon, The Dynamics of Intense Work Groups: A Study of British String Quartets, Adm. Sci. Q., vol. 36, no. 2, pp. 165-186, 1991.

[8] P. S. Adler, B. Goldoftas, D. I. Levine, P. S. Adler, B. Goldoftas, and D. I. Levine, Flexibility versus efficiency? A case study of model changeovers in the Toyota production system, Organ. Sci., vol. 10, no. 1, pp. 43-68, 1999.

[9] W. K. Smith and M. L. Tushman, Managing Strategic Contradictions : A Top Management Model for Managing Innovation Streams, Organ. Sci., vol. 16, no. 5, pp. 522-536, 2005.

[10] J. D. Margolis and J. P. Walsh, Misery loves companies: Rethinking social initiatives by business, Adm. Sci. Q., vol. 48, no. 2, pp. 268-305, 2003.

[11] K. K. Cetina, T. R. Schatzki and E. Von Savigny, The practice turn in contemporary theory. Routledge, London, 2005.

[12] J. Whyte, Knowledge practices in design : The role of visual representations as ' epistemic objects ,"” Organization Studies, April, 2015, https://doi.org/10.1177/0170840608083014.

[13] P. R. Carlile, Transferring, translating, and transforming: An integrative framework for managing knowledge across boundaries, Organ. Sci., vol. 15, no. 5, pp. 555-568, 2004.

[14] A. P. Baltensperger, T. C. Mullet, M. S. Schmid, G. R. W. Humphries, L. Kövér, and F. Huettmann, Seasonal observations and machine-learning-based spatial model predictions for the common raven (Corvus corax) in the urban, sub-arctic environment of Fairbanks, Alaska, Polar Biol., vol. 36, no. 11, pp. 1587-1599, 2013.

[15] N. Slack and M. Lewis, Operations strategy. Pearson Education, Upper Saddle River, 2002.

[16] R. K. Yin, Case study research: Design and Methods, 3rd ed. Sage Publications, Thousand Oaks, 1994.

[17] T. W. Lee, Using qualitative methods in organizational research. Sage, Thousand Oaks, 1999.

[18] P. Coughlan and D. Coghlan, Action research for operations management, Int. J. Oper. Prod. Manag., vol. 22, no. 2, pp. 220-240, 2002.

[19] A. Bryman and E. Bell, Business research methods. Oxford University Press, Boston, 2015.

[20] M. B. Miles and A. M. Huberman, Qualitative Data Analysis, 2nd ed. Sage, London, 1994.

[21] K. Tybjerg, Exhibiting Epistemic Objects, Museum and society, vol. 15, no. 3, pp. 269-286, 2017.

[22] J. R. Austin, Transactive Memory in Organizational Groups : The Effects of Content, Consensus , Specialization, and Accuracy on Group Performance, vol. 88, no. 5, pp. 866-878, 2003. 